\title{
Editorial
}

\section{Stent-in-Stent for Malign Obstruction: Should We Go Back to a Place Where We Were Happy?}

\author{
Francisco Baldaque-Silva
}

Endoscopy Unit, Department of Upper Abdominal Diseases, Karolinska University Hospital and Karolinska Institute, Stockholm, Sweden

\section{Dear Editor,}

Malignant gastrointestinal strictures are a late complication of advanced gastrointestinal or pancreatobiliary malignancies [1]. These advanced cancers are associated with a poor prognosis and a median overall survival of $<1$ year [2,3]. Malign strictures hamper patients' quality of life and may cause nausea, vomiting, intolerance to oral feeding, and abdominal discomfort. These contribute to profound weight loss, malnutrition, delays in initiation of proper treatment, and ultimately shorten life expectancy [4]. The primary aims of palliation for these patients are to relief obstruction-related symptoms and to restore oral intake in order to improve patients' quality of life.

Traditionally, malignant gastrointestinal strictures, namely malign gastric outlet obstruction, were treated with surgical bypass through gastrojejunostomy. More recently, endoscopic self-expandable metal stents (SEMS) have emerged as an alternative, especially in patients with a limited life span or with poor health status. Most studies show that the use of SEMS in malignant gastric outlet obstruction has the benefits of a quicker resumption of oral intake, usually the day after stent placement, and a shorter hospital stay with reduced costs [5]. As such, there has been enthusiasm for stent placement as first-line treat- ment. However, SEMS are associated with an increased recurrence of stricture and symptoms, with the need for further intervention, compared to surgery [5]. However, it is not possible to draw further conclusions on these and other measured outcomes due to the low number of eligible studies, engaging a small number of patients. Furthermore, in several centers, SEMS have been used in patients with poorer health status, while gastrojejunostomy may be more suitable for patients with better health status. This causes a big selection bias in the published literature, which results in low-quality evidence.

Due to advances in oncological treatment, patients treated with SEMS for malign gastric outlet obstruction can live longer than expected. In these cases, SEMS are often dysfunctional mostly due to occlusion, that is the most frequent complication of SEMS, occurring in 13$26 \%$ of the cases [6]. Management of dysfunctional SEMS is controversial, potentially involving secondary stent-instent placement. Reports on the use of gastroduodenal SEMS after first stent dysfunction are limited. In this issue of GE Portuguese Journal of Gastroenterology, Patita et al. [7] aim to bring new light on the efficacy and safety in the placement of a second SEMS using the stent-in-stent technique. This technique involves the insertion of a stent

\begin{tabular}{ll}
\hline KARGER & ( ) 2020 Sociedade Portuguesa de Gastrenterologia \\
& Published by S. Karger AG, Basel \\
karger@karger.com & This article is licensed under the Creative Commons Attribution- \\
www.karger.com/pjg & $\begin{array}{l}\text { NonCommercial-NoDerivatives 4.0 International License (CC BY- } \\
\text { NC-ND) (http://www.karger.com/Services/OpenAccessLicense). } \\
\text { Usage and distribution for commercial purposes as well as any dis- } \\
\text { tribution of modified material requires written permission. }\end{array}$ \\
JOPEN ACCESS &
\end{tabular}

Francisco Baldaque-Silva

Endoscopy Unit, Department of Upper Abdominal Diseases

Karolinska University Hospital and Karolinska Institute

Kirurgigatan 53, SE-141 86 Stockholm (Sweden)

fbaldaquesilva@gmail.com 
into the stenotic portion of the prior stent [8]. Authors report their retrospective series in patients with malignant strictures, mostly gastric outlet obstruction, providing objective data, including technical and clinical success rates, adverse events, and stent patency. Patita et al. [7] describe a well characterized series of 12 patients (11 with malign gastric outlet obstruction), with the particularity that all had disfunction of an uncovered stent, which was treated with the deployment of a new covered stent. This study confirms what has been known to gastroenterologists: in experienced hands, stent-in-stent technique has a high rate of technical and clinical success, and a low rate of procedural adverse events. In fact, in this study there was $100 \%$ technical success and $91.7 \%$ clinical success with the insertion of covered metal stents. There were neither complications nor need for reintervention. The median patency time after placement of the uncovered and covered stent were 71 and 163 days, respectively.

Despite technical success and luminal patency, clinical symptoms in patients with malignant gastric outlet obstruction might not resolve. Several factors may hamper clinical success of a SEMS deployed successfully. Prolonged gastric obstruction causes dilation of the stomach and weakening of the muscle wall, impairing gastric emptying even when luminal patency is reestablished. Another factor may be gastroparesis caused by chemo- or radiotherapy (present in 11/12 patients in the study by Patita et al. [7]) or tumor infiltration of neural plexuses. Furthermore, advancing malignancy deteriorates patient condition and causes significant anorexia. Finally, obstruction distal to the stent is common with peritoneal carcinomatosis (present in 6/12 patients in the study by Patita et al. [7]). As a result, when patients do not improve after SEMS placement or show obstructive symptoms after initial improvement, it is important to exclude these different factors. In this context, a gastrointestinal series is important and enables assessment of patency and of possible distal obstructions.

Previous studies described adverse events related to SEMS deployment such as bleeding and perforation in 4.6 and $1.9 \%$ of the cases, respectively, in the context of malign gastric outlet obstruction [9]. The study by Patita et al. [7] corroborates more recent studies, showing that stent-in-stent deployment in this context is associated with no or negligible adverse events [10]. This highlights the value of specialized teams in this setting and the safety of the technique.

Agatha Christie famously wrote in 1977, "never go back to a place where you have been happy." According to the results from Patita et al. [7], in case of stent dysfunc- tion, one should go back to the stent irrespective of previous clinical success or cause of stent dysfunction. One should go back and deploy a covered stent, this strategy having a high efficacy and safety.

For those who want to follow Agatha Christie's quote, there is a new alternative for the treatment of malign gastric outlet obstruction: endoscopic ultrasound-guided gastroenterostomy (EUS-GE) using lumen-apposing metal stents. This technique has been increasingly used in reference centers across the globe, but there is still limited literature on its use in this setting. However, published data comparing EUS-GE with enteral stent placement show identical technical success but increased clinical success with EUS-GE (95.8 vs. $76.3 \%, p=0.042$ ) and lower need for re-intervention ( 32.0 vs. $8.3 \%, p=0.021$ ), with no significant differences in the rate of adverse events [11].

In conclusion, symptomatic malignant gastric outlet obstruction is common with gastrointestinal malignancy and should be promptly and effectively addressed. The proper approach should be individualized on the basis of disease prognosis, patient's preference, and expertise of the medical center. Stent-in-stent strategy using a covered SEMS after dysfunction of an uncovered SEMS is a good option. EUS-GE might be a good alternative in the appropriate setting.

\section{Conflict of Interest Statement}

The author reports no disclosures related to this article.

References

1 Ye BW, Chou CK, Hsieh YC, Li CP, Chao Y, Hou MC, et al. Metallic Stent Expansion Rate at Day One Predicts Stent Patency in Patients with Gastric Outlet Obstruction. Dig Dis Sci. 2017 May;62(5):1286-94.

2 Tada M, Nakai Y, Sasaki T, Hamada T, Nagano R, Mohri D, et al. Recent progress and limitations of chemotherapy for pancreatic and biliary tract cancers. World J Clin Oncol. 2011 Mar;2(3):158-63.

3 Park SC, Chun HJ. Chemotherapy for advanced gastric cancer: review and update of current practices. Gut Liver. 2013 Jul;7(4): 385-93.

4 No JH, Kim SW, Lim CH, Kim JS, Cho YK, Park JM, et al. Long-term outcome of palliative therapy for gastric outlet obstruction caused by unresectable gastric cancer in patients with good performance status: endoscopic stenting versus surgery. Gastrointest Endosc. 2013 Jul;78(1):55-62. 
5 Upchurch E, Ragusa M, Cirocchi R. Stent placement versus surgical palliation for adults with malignant gastric outlet obstruction. Cochrane Database Syst Rev. 2018 May; 5(5):CD012506.

6 Sasaki T, Isayama H, Maetani I, Nakai Y, Kogure H, Kawakubo K, et al. Japanese multicenter estimation of WallFlex duodenal stent for unresectable malignant gastric outlet obstruction. Dig Endosc. 2013 Jan;25(1): $1-6$.

7 Patita M, Castro R, Libânio D, Bastos RP, Silva $\mathrm{R}$, Dinis-Ribeiro $\mathrm{M}$, et al.: Covered Metal
Stent after Dysfunction of Uncovered Stents for Palliation of Gastrointestinal Malignant Obstruction. GE Port J Gastroenterol.DOI: 10.1159/000507200.

8 Kim CG, Choi IJ, Lee JY, Cho SJ, Kim SJ, Kim MJ, et al. Outcomes of second self-expandable metallic stent insertion for malignant gastric outlet obstruction. Surg Endosc. 2014 Jan; 28(1):281-8.

9 Tringali A, Didden P, Repici A, Spaander M, Bourke MJ, Williams SJ, et al. Endoscopic treatment of malignant gastric and duodenal strictures: a prospective, multicenter study. Gastrointest Endosc. 2014 Jan;79(1): 66-75.

10 Mo JW, Kim YM, Kim JH, Shin SY, Youn YH, Park H. Clinical outcomes after multiple selfexpandable metallic stent placement using stent-in-stent technique for malignant gastric outlet obstruction. Medicine (Baltimore). 2020 May;99(21):e19432.

11 Ge PS, Young JY, Dong W, Thompson CC. EUS-guided gastroenterostomy versus enteral stent placement for palliation of malignant gastric outlet obstruction. Surg Endosc. 2019 Oct;33(10):3404-11. 